Sri Lanka J. Aquat. Sci. 7 (2002): 1-22

\title{
Tilapias and Indigenous Fish Biodiversity in Sri Lanka
}

\author{
C. H. FERNANDO ${ }^{1 *}$, R.R.A.R. SHIRANTHA ${ }^{2}$, M.J.S. WIJEYARATNE ${ }^{2}$ \\ and P.R.T. CUMARANATUNGA ${ }^{3}$
}

${ }^{1}$ Department of Biology, University of Waterloo, Waterloo, Ontario, Canada N2L 3G1

${ }^{2}$ Department of Zoology, University of Kelaniya, Kelaniya 11600, Sri Lanka

${ }^{3}$ Department of Fisheries Biology, University of Ruhuna, Matara, Sri Lanka

*Corresponding author (E-mail: chfernan@sciborg.uwaterloo.ca)

\begin{abstract}
Some species of tilapias are now found worldwide in natural and artificial habitats in the tropics and sub tropics. Claims have been made from time to time that tilapias have displaced indigenous fishes and damaged fish culture. In this paper an attempt is made to examine some of these statements and evaluate whether there is a basis for such claims. In Sri Lanka, introduced tilapias are found mainly in man made reservoirs and still there are no records of established populations of exotic tilapias in the river systems in the country where indigenous and endemic freshwater fish species are found. The major threats to freshwater fish biodiversity include habitat degradation and overexploitation for the ornamental fish trade. In Sri Lanka, introduction of tilapias to lacustrine waters has been beneficial in terms of contributing to fish production. Tilapias have been in natural and artificial habitats throughout the tropics and the sub-tropics for over 50 years. Considering the immense number of introductions of tilapias into individual habitats in many parts of the tropics and subtropics, surprisingly few substantiated cases of their damaging indigenous fish communities have so far been recorded. Some of these claims of cases of presumed or real damage to local fish stocks are ambiguous or ware unsubstantiated speculations. To expect absolutely no negative effects at all on the indigenous fishes by tilapias is unrealistic. On the other hand substantial quantities of tilapias are now harvested from reservoirs or raised in culture where no such enterprises existed earlier.
\end{abstract}

\section{Introduction}

The cichlid tribe Tilapiine includes a large number of species. Trewavas (1983) defined Tilapiine as an African and Levantine assemblege, which included 


\section{C.H. Fernando et al.}

14 genera. The three tilapiine genera Oreochromis, Sarotherodon and Tilapia, especially the larger species most commonly caught in the wild fisheries or used in aquaculture are conveniently known as 'the tilapias' (McAndrew 2000). In this paper we use the common name of tilapia to describe the species, which are of interest in the inland capture fisheries and aquaculture in most parts of the world. Some species of Oreochromis, Sarotherodon and Tilapia are now found worldwide in natural and artificial habitats in the tropics and sub tropics (Welcomme, 1992). Their original home is Africa and most species of tilapias have entered different countries throughout the tropical world through deliberate introduction. According to the information given in the website, www.fao.org/fi/statist/dias/index.htm, there are 70,287 and 12 records of introductions world wide of Tilapia spp ( 05 species), Oreochromis spp (11 species) and Sarotherodon spp (02 species) respectively. A list of some cichlid species, the number of countries into which they have been introduced, and their environmental and socioeconomic effects, as reported in this website are given in Table 1. According to this information, most of the cases of introductions do not mention any significant problems either ecologically or socioeconomically and in fact there are many cases that indicate benefits.

Table 1. List of tilapia species and the number of countries into which they have been introduced and their ecological and socioeconomic effects: A -adverse; B Beneficial; U -unknown (Source: www.fao.org/fi/statist/dias/index.htm).

\begin{tabular}{llllllll}
\hline Species & \multirow{2}{*}{$\begin{array}{l}\text { Number } \\
\text { of }\end{array}$} & \multicolumn{3}{c}{ Ecological effects } & \multicolumn{3}{l}{$\begin{array}{l}\text { Socioeconomic } \\
\text { effects }\end{array}$} \\
\cline { 3 - 8 } & countries & A & B & U & A & B & U \\
\hline Oreochromis mossambicus & 92 & 06 & 12 & 74 & 03 & 26 & 63 \\
O. niloticus & 80 & 03 & 13 & 64 & 0 & 32 & 48 \\
O. aureus & 42 & 0 & 02 & 40 & 0 & 08 & 34 \\
Tilapia rendalli & 32 & 01 & 01 & 30 & 0 & 04 & 28 \\
T. zilli & 30 & 0 & 02 & 28 & 0 & 03 & 27 \\
O. urolepis hornorum & 21 & 0 & 0 & 21 & 0 & 01 & 20 \\
O. macrochir & 21 & 0 & 0 & 21 & 0 & 01 & 20 \\
O. spilurus & 9 & 0 & 01 & 08 & 0 & 01 & 08 \\
\hline
\end{tabular}

Oreochromis mossambicus (Peters) was spread widely in the 1950's. From the point of view of international introductions, Cyprinus carpio and Onchorhynchus mykiss, which have been introduced to 124 and 99 countries respectively have a wider distribution due to introductions than $O$. mossambicus (Source: www.fao.org/fi/statist/dias/index.htm). Later other species like Oreochromis niloticus (L.) and Tilapia rendalli (Boulanger) were also introduced into many countries. Introductions of $O$. mossambicus and $O$. niloticus in the world are shown in Fig. 1. Their spread has been well documented and their impressive 
role in fish culture has been the subject of five international meetings in Asia, Africa and North and South America (Fishelson \& Yaron 1983; Pullin et al. 1986, 1996; Fitzsimmons 1997; Fitzsimmons \& Filho 2000).

It is axiomatic that most tilapias are lacustrine-adapted fishes as they are capable of completing the entire life cycle in the lacustrine habitats as opposed to riverine fishes, some stages of the life cycle of which are dependent on the riverine habitats (Fernando \& Holčik 1991). Before the appearance of tilapias on the scene of lacustrine fisheries, outside their natural range in Africa, in the tropics and sub tropics, the indigenous freshwater fish yields were very low to insignificant (Fernando \& Holčik, 1991). These figures were raised to the high levels of fish yields in African lakes and reservoirs by tilapias. Fish yields in extra -African lakes and reservoirs had previously been bolstered to a small extent by stocking with temperate carps at high cost and low return (Petr, 1988; Sugunan, 1995). This sequence of events is well documented in the literature and most recently by Fernando et al. (1998). Claims have been made from time to time that tilapias have damaged sub-optimal fisheries or those based on stocked carps and other fishes mainly in India and that they also reduced the biodiversity of indigenous fishes. Claims were also made that their impact on the fisheries of lakes and reservoirs was not widespread. Myers (1955) predicted that there would be dire consequences if tilapias were introduced into Central America. He based this statement on an aerial survey of the region but no study. Reidel (1965) who actually studied tilapias in Nicaragua suggested otherwise and encouraged the introduction of tilapias to the region. Lévêque (1998) has discussed fish introductions in Africa in detail. He states that while the introduction of a wide range of freshwater fish has been recorded during the past 150 years, their impact has not been spectacular except in a few cases. The negative impacts of introductions have been mainly due to piscivores. Meanwhile, changes in freshwater habitats caused by human activities have been pervasive and profound. His comments are applicable worldwide. Tilapias are not piscivores and there have been enormous ecological changes wrought throughout the world by the building of reservoirs that must be counted in the millions. River systems have been altered by damming and channelling to provide the sites for these reservoirs. The impacts of tilapias on indigenous fishes in reservoirs have been commented upon by researchers since the nineteen sixties. Much of these comments were gathered by Fernando (1993). Few adverse effects on the indigenous fish fauna have been noted. As shown in Table 1, out of the 369 introductions of tilapias (Oreochromis, Sarotherodon and Tilapia spp.) reported, 359 cases either report beneficial effects or do not report any negative ecological and/or socio-economic problems. In recent publications by Beveridge and McAndrew (2000) and the review of this book by Lévêque (2002) and Goudswaard et al. (2002) some cases of damage to indigenous fishes have been reported but these workers also state that many cases of benefits to the fisheries have resulted from the introductions of tilapias throughout the tropics. This indicates the need for 


\section{C.H. Fernando et al.}

rigorous examination of the claims, which have been made that introduced tilapias have detrimental impacts on the indigenous fish fauna of Sri Lanka that is basically riverine.

\section{Materials and Methods}

Since Pethiyagoda $(1994,1998)$ mentioned that there are established populations of $O$. mossambicus in riverine habitats of Sri Lanka, we have attempted to analyse data on species richness in some rivers of the country. Intensive sampling was carried out using cast nets, drag nets and electrofishing. Information in published papers on the possible ecological and socio-economic impacts of introduced African cichlids is also used to evaluate whether there is a basis for elaims that there is an adverse effect of $O$. mossambicus on the indigenous fish fauna in Sri Lanka. In addition, attempts were made to explain the actual impact of introduced tilapias in Sri Lanka on the basis of experience of the authors who have been doing field work on inland fisheries for a period of 50, 5, 25 and 15 years (in order of authors) respectively. Also we have attempted to evaluate the merits and demerits of introduction of tilapias in relation to aims of fisheries management in different parts of the world.

\section{Results and Discussion}

Pullin et al. (1997) studied the environmental impacts of $O$. niloticus introductions in five countries and concluded that there were no adverse environmental impacts or reduction of biodiversity of indigenous fishes. Dudgeon (2000) in his evaluation of threats to biodiversity in tropical Asian rivers and streams mentioned five different threats but did not mention fish introduction as one of these threats. Jang et al. (2002) found tilapias to be very rare in the river systems they investigated in South Korea. Tilapias are lacustrine adapted fishes and colonize lakes and reservoirs in the tropics readily. They have colonized almost all the reservoirs in Sri Lanka shown in Fig. 2. Most of the indigenous cyprinids, characids and catfishes that are primary freshwater fishes live at the mouths of rivers that enter lakes and reservoirs (Fernando 1993). Most of these species must migrate upstream to breed during floods (Fernando 1993). Tilapias do not have to leave standing waters to breed. They may be washed into rivers via irrigation channels during draw down of water for irrigation. There is an extensive river system of 103 rivers in Sri Lanka (Fig. 3). Also irrigation channels add to running waters (Fig. 4). Some details on recent observations made in five river basins in Sri Lanka are given in Table 2. During 278 fish collecting field visits in the Kelani river basin, 66 specimens of $O$. mossambicus were caught near a rubber estate in the village Dehiowita and in the village Atulugama. In the Kalu river basin, only 4 specimens of $O$. mossambicus were caught during 240 fishing trials with cast nets and scoop 
Tilapia and indigenous fish in Sri Lanka

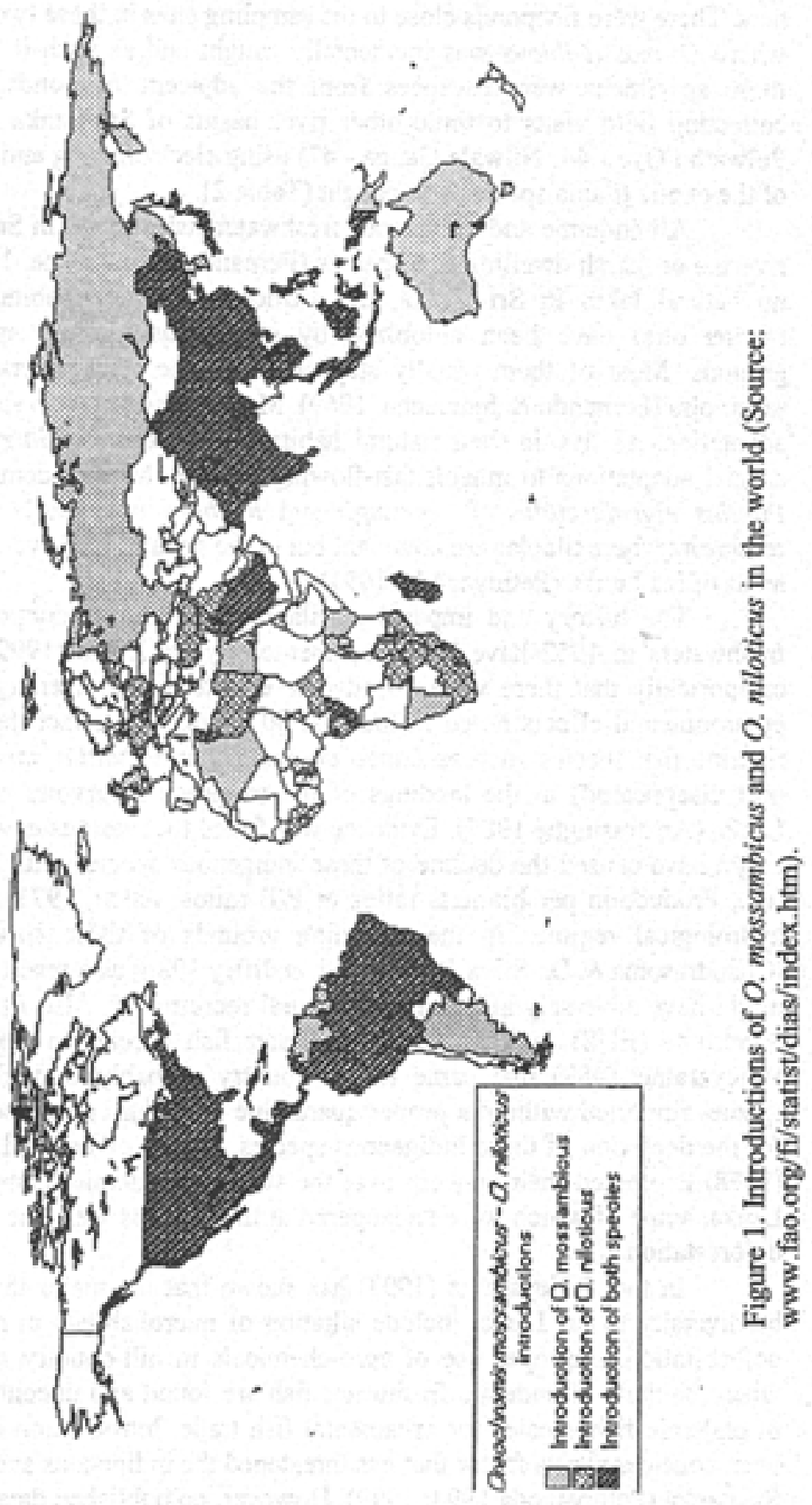




\section{C.H. Fernando et al.}

nets. There were fishponds close to the sampling sites in these two river basins from where $O$. mossambicus was incidentally caught and as such it is very likely that these specimens were escapees from the adjacent fishponds. During the fish collecting field visits to three other river basins of Sri Lanka (Gin Ganga - 42; Polwathu Oya - 44; Nilwala Ganga - 47) using electrofishing and cast netting, none of the exotic tilapia species was caught (Table 2).

All endemic and indigenous freshwater fish species in Sri Lanka are either riverine or marsh dwelling fish species (Fernando \& Indrasena, 1969). As there are no natural lakes in Sri Lanka, the artificial lacustrine habitats in the country (=reservoirs) have been colonized by indigenous riverine species as feeding grounds. Most of them usually stay close to where the rivers or streams enter reservoirs (Fernando \& Indrasena, 1969). Most indigenous fish species have special adaptations to live in their natural habitats. For example Garra ceylonensis has special adaptations to inhabit fast-flowing streams. Most endemic species such as Puntius nigrofasciatus, $P$. cumingii and Rasbora vaterifloris are not found in reservoirs where tilapias are abundant but in the streams and rivers in the central hill areas of Sri Lanka (Pethiyagoda, 1991).

The history and impacts of tilapia after its introduction into Sri Lanka freshwaters in 1952 have been documented by De Zylva (1999). He states quite categorically that there were no adverse effects on biodiversity or other adverse environmental effects noted in the past 50 years. It is a fact that some idigenous riverine fish species such as Labeo dussumieri and Puntius sarana have declined (not disappeared) in the landings of the irrigation reservoirs of dry zone of Sri Lanka (Amarasinghe 1987). Evidence was found that various environmental factors might have caused the decline of these indigenous species with low tumover rates (i.e., Production per biomass ratios or P/B ratios; Allen, 1971). Radically altered hydrological regimes in the spawning grounds of these species in the rivers (Chandrasoma \& De Silva 1981; Smith \& Jiffry 1986) as a result of river damming, might have adversely affected their natural recruitment. Also Epizootic Ulcerative Syndrome (EUS) in indigenous freshwater fish species in Sri Lanka (Costa \& Wijeyaratne 1989) that came to the country probably through ornamental fish species imported without a proper quarantine procedure may also have contributed for the depletion of these indigenous species. On the other hand, Kortmulder et al. (1978) expressed their concern over the status of endemic freshwater fishes in Sri Lanka, some of which were endangered at that time as well due to overfishing and deforestation.

In fact Wijeyaratne (1993) has shown that the major threats to freshwater biodiversity in Sri Lanka include siltation of microhabitats in hill streams due to deforestation, improper use of agro-chemicals in hill-country areas of Sri Lanka where habitats of endemic freshwater fish are found and uncontrolled exploitation of endemic fish species for ornamental fish trade. Introduction of tilapias has also been considered as a factor that has threatened the indigenous and endemic fishes in Sri Lanka (Pethiyagoda 1994; 1999). However, no published data are yet available 
Tilapia and indigenous fish in Sri Lanka

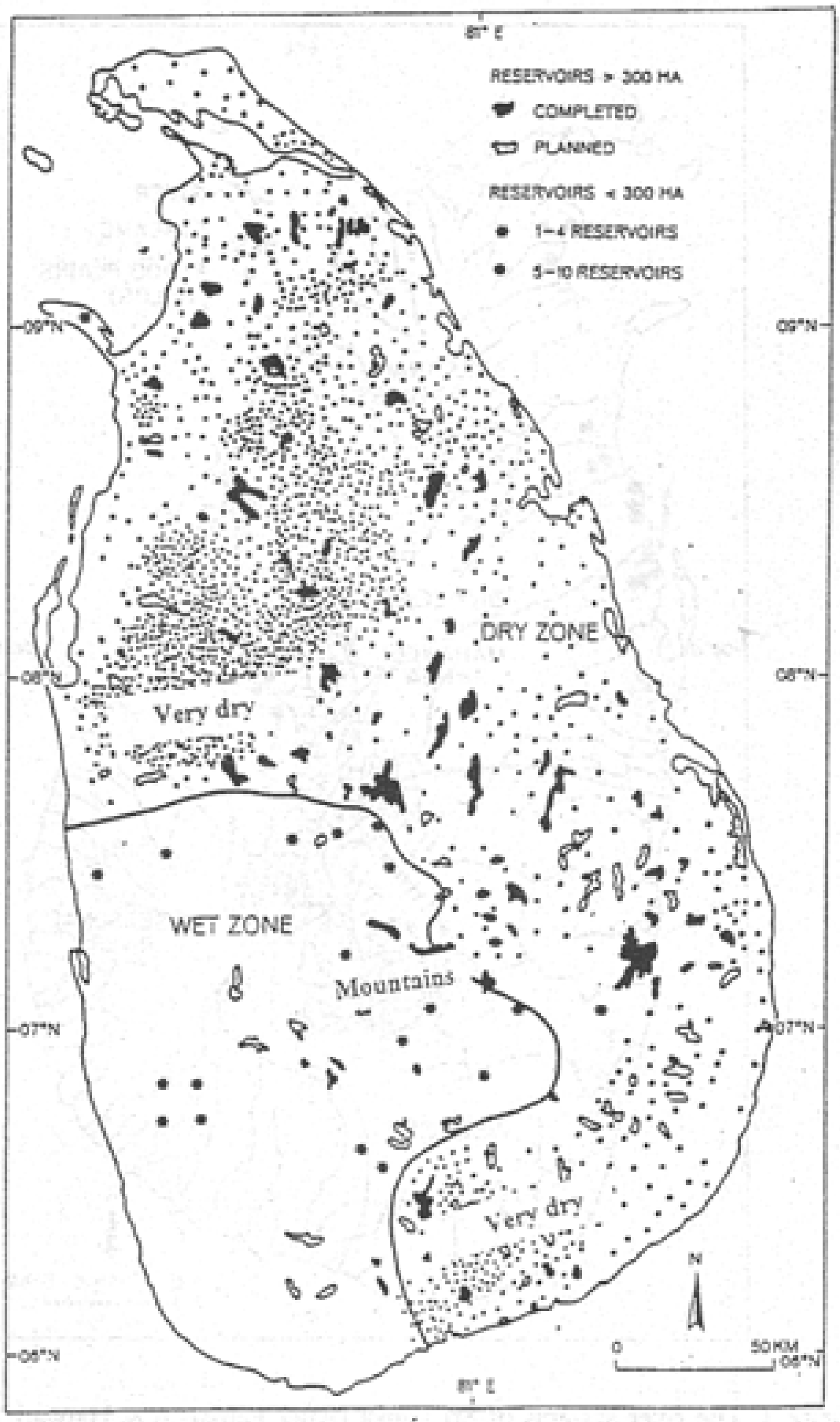

Figure 2. Distribution of reservoirs in Sri Lanka. All these reservoirs have been colonized by tilapias (After Femando 1993) 


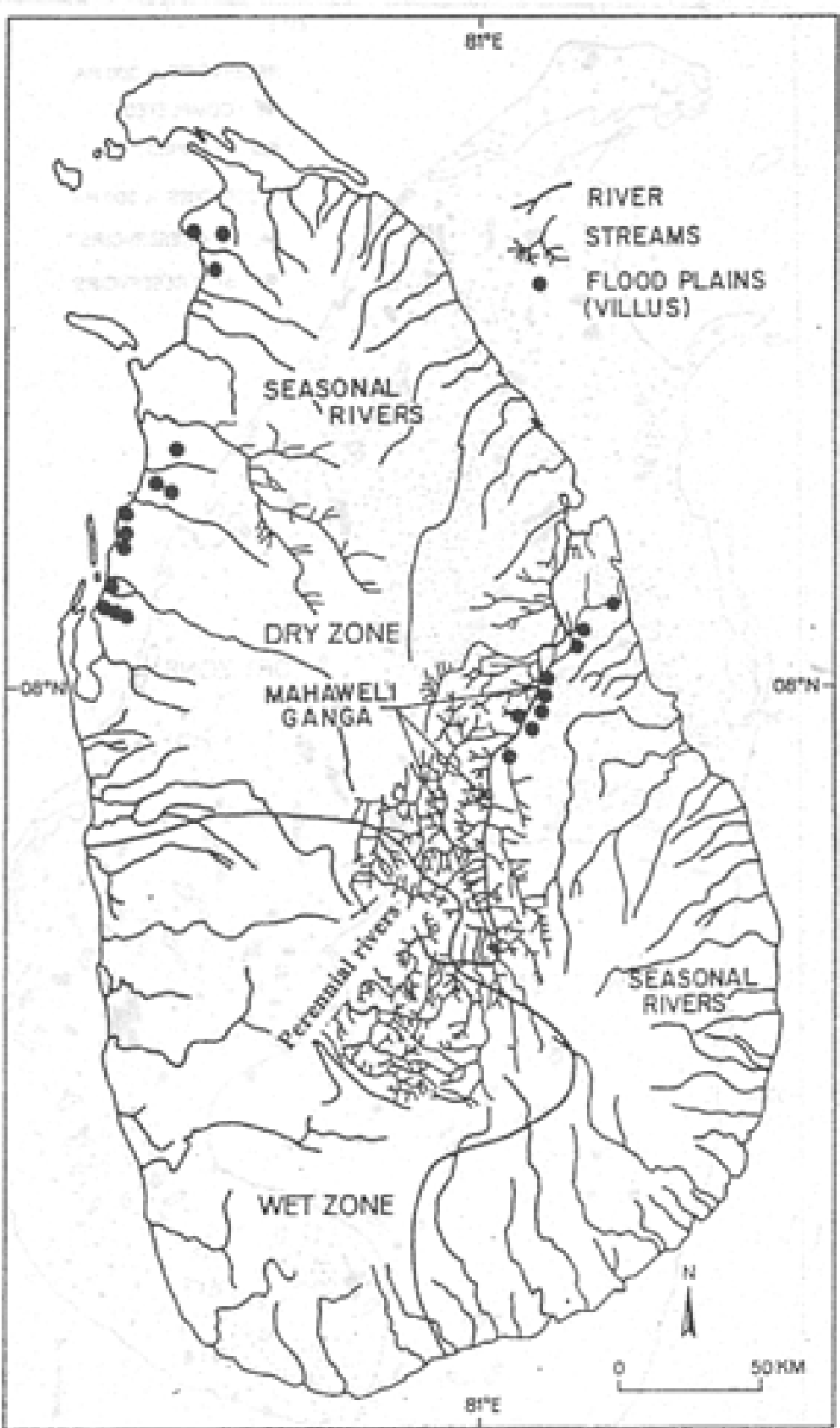

Figure 3. The river systems of Sri Lanka (After Femando \& Halwart 2001). The river and stream system forms a closely-knit honeycomb in the wetter parts of the country as shown for one river in part. 
Tilapia and indigenous fish in Sri Lanka

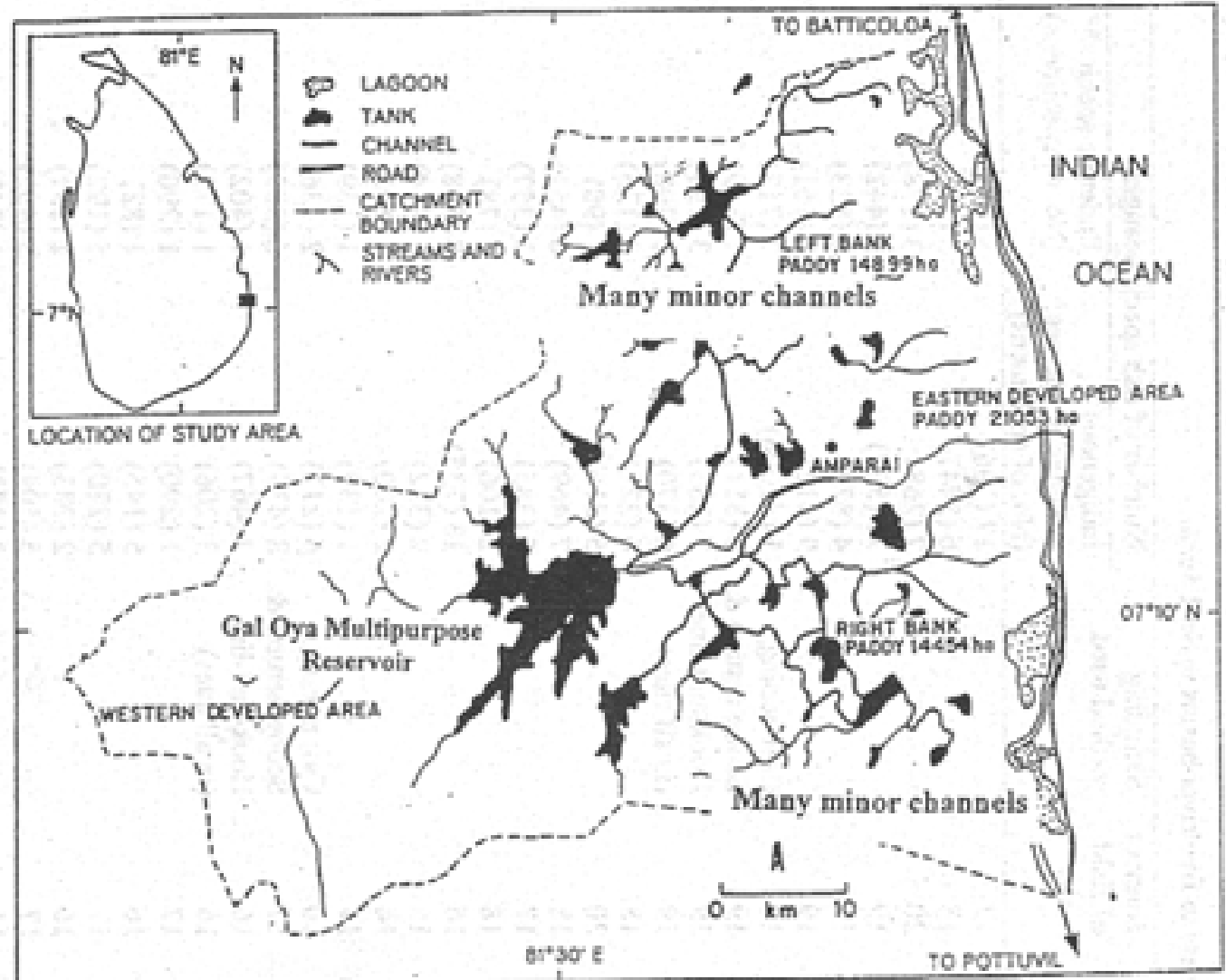

Figure 4. A major irrigation system (Gal Oya) in the Ampara district, Sri Lanka showing reservoirs, natural streams and irrigation channels. Only the large channels are shown but channels lead right up to rice fields (After Fernando \& Halwart 2001). 


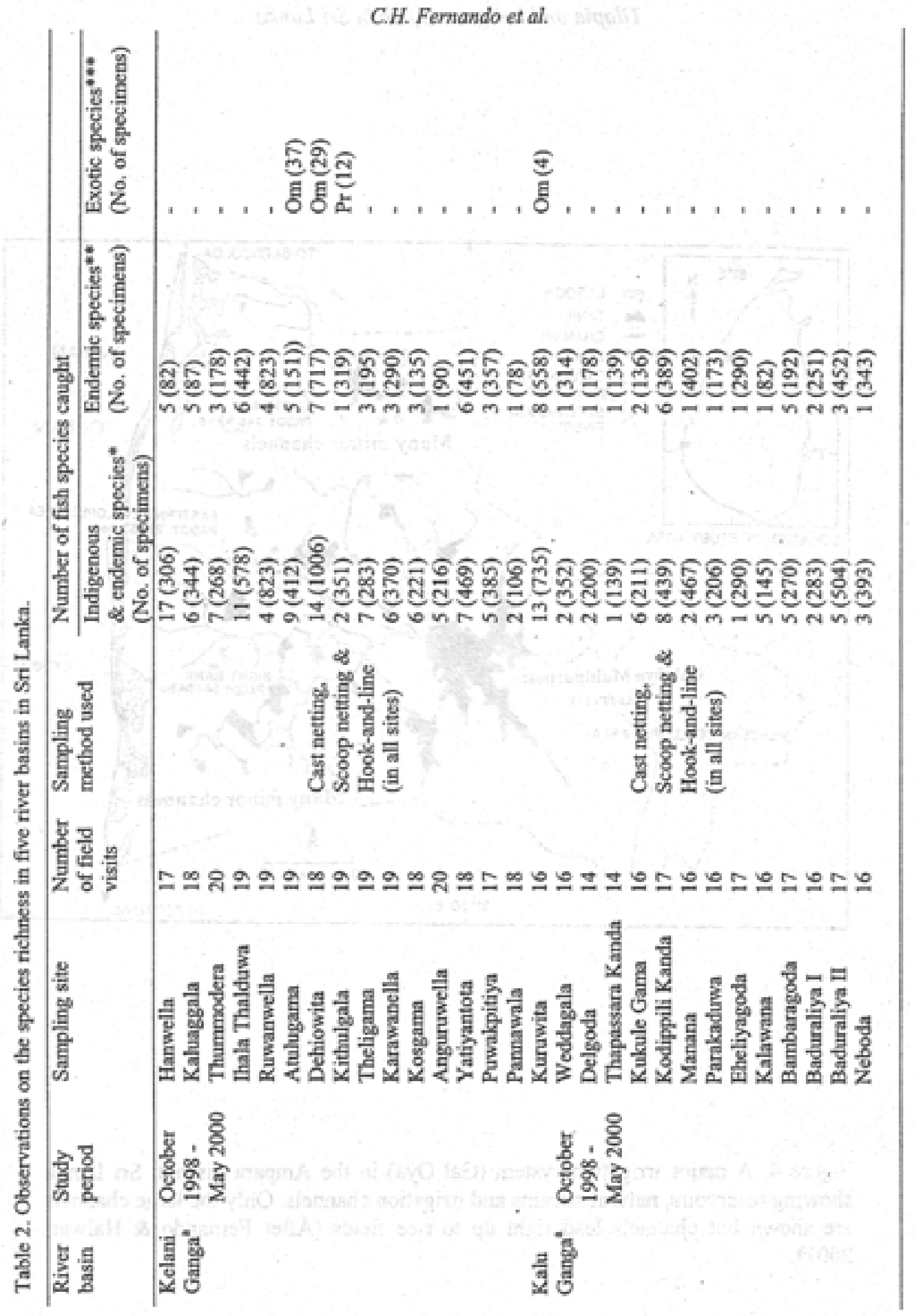




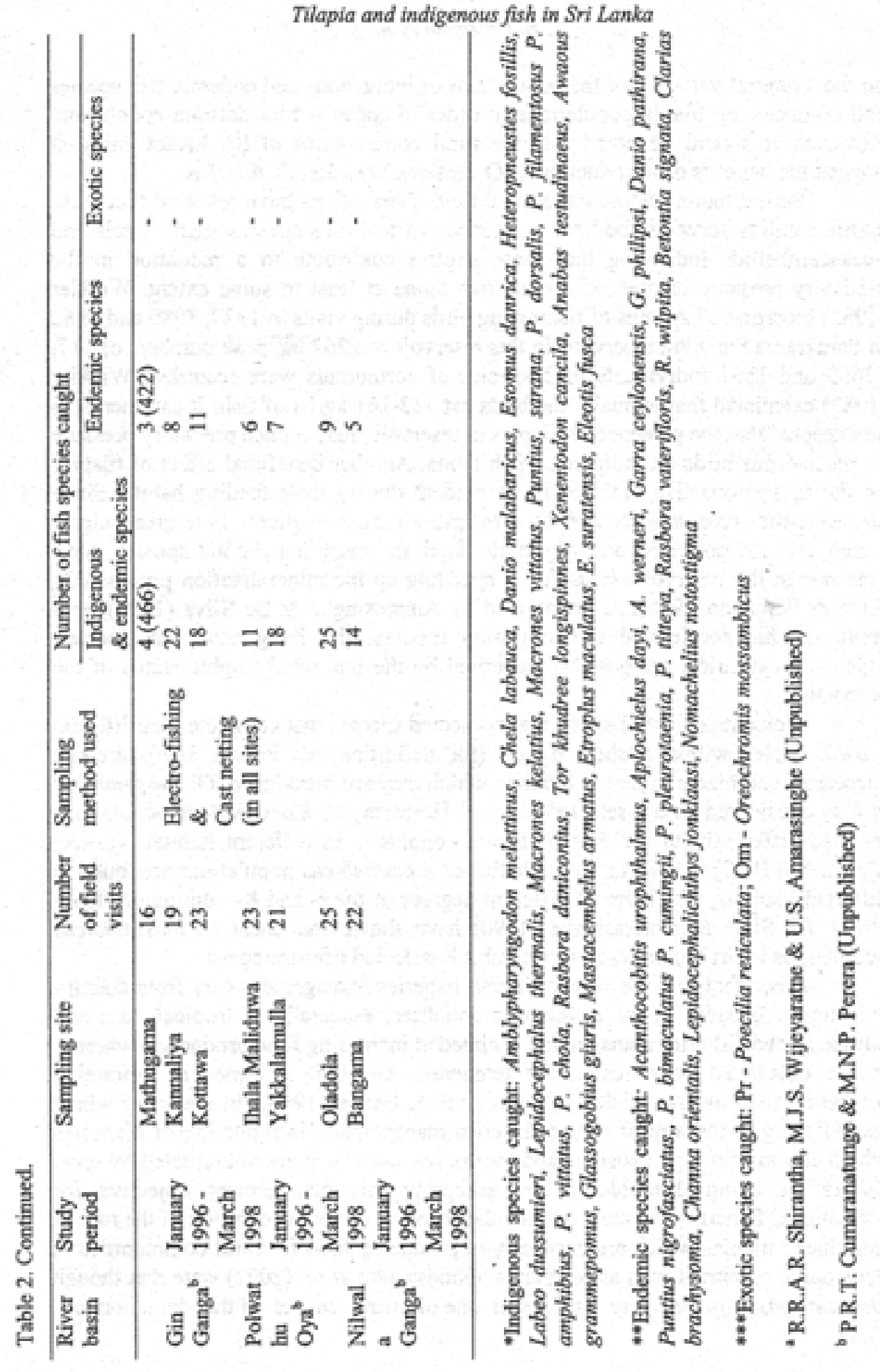


on the temporal variation of the populations of indigenous and endemic fish species and co-oceurring tilapia populations in order to come in to a definite conclusion. However, it should be noted that the rural communities of Sri Lanka enjoy at present the benefits of introduction of $O$. mossambicus and $O$. niloticus.

Furthermore, the laboratory and field observations have revealed that these exotic cichlids serve as food for indigenous carnivorous species such as eels and mastacembellids indicating that these exotics contribute to a reduction in the predatory pressure on the indigenous fish fauna at least to some extent. Winkler (1983) recorded 27 species of fish-eating birds during visits in 1979, 1980 and 1982 in Parakrama Samudra reservoir. In this reservoir of 2262 ha, peak numbers of 117 , 13699 and 1851 individuals of 3 species of cormorants were recorded. Winkler (1983) calculated that annually the birds eat $112-161 \mathrm{~kg} / \mathrm{ha}$ of fish. It can therefore be expected that the presence of tilapias in reservoirs may reduce predatory pressure by piscivorous birds on indigenous fish fauna. Another beneficial effect of tilapias on the indigenous fish biodiversity is evident due to their feeding habits. Since Oreochromis mossambicus and $O$. niloticus are able to digest blue-green algae, which are not preferred and digestible food for most indigenous species, their presence in the reservoirs is useful in speeding up the mineralization process (De Silva \& Fernando 1980). As mentioned by Amarasinghe \& De Silva (1992), as a result of this accelerated mineralization process, the indigenous fish species, especially cyprinids, are possibly benefited by the improved trophic status of the reservoirs.

Welcomme (1988) stated that r-selected species that complete their life and growth cycles within a short period (for definition see Pianka 1970) are the successful colonizers in new habitats to which they are introduced. $O$. mossambicus is also considered as a r-selected species. However, $O$. mossambicus populations respond differently to the environmental conditions in different habitats (LoweMcConnell 1982) so that it is possible that $O$. mossambicus populations are found in different habitats, which are of different degrees of the $\mathrm{r}$ - and $\mathrm{K}$ - continuum (Horn 1978). De Silva \& Amarasinghe (1990) have shown that most $O$. mossambicus populations in Sri Lanka reservoirs exhibit K-selected life strategies.

It is a fact that the aims of inland fisheries management vary from country to country. Broadly in the developing countries, especially in tropical Asia and Africa, inland fisheries management is aimed at increasing food production whereas in the developed countries in the temperate world, it is aimed at promoting recreation such as sport fishing (Welcomme \& Bartley 1998). In countries where sport fishing is the aim of inland fisheries management, introduction of a species which can sustain high densities and biomasses and which are not targeted by sport fishers, as being desirable. While accepting this management objective for recreational fisheries, we must on the other hand, give due recognition of the role of introduced tilapias which are necessary in producing food for rural communities in developing countries such as Sri Lanka. Goudswaard et al. (2002) state that though Oreochromis niloticus may have been one of many causes of the depletion of 
indigenous species of cichlids in Lake Victoria, the fisheries benefits of the introduced $O$. niloticus are considerable and therefore its elimination is not desirable. A good example of the attitude of sport fisheries interests is found in Australia where $O$. mossambicus is considered and designated a pest. Arthington (1989) stated that "in other countries (outside Australia) species of tilapia all have become pests in productive fisheries, aquaculture systems and natural environments". However, later this has been modified (Bludhorn \& Arthington 1990). Tilapias remain defined as a noxious group whose introduction is prohibited in Australia. However, it is present in Australia and is the most important food fish in Papua New Guinea next to tuna that is caught in trawlers offshore (Coates 1992).

Vaas \& Sachlan (1952) had stated that common carp and two indigenous fishes were stocked into a 25 ha reservoir in Java and the prominent fishes in the catch included tilapias and three other species. Carps were not mentioned. However Lowe-McConnell $(1975,1987)$ mentioned carp among the prominent fish in the catch and did not mention tilapias. In Lowe-McConnell (1987) the following statement appears. "In a few places (notably Sri Lanka which lacked any lacustrine species and in Madagascar), stocking with exotic species such as tilapias has boosted production. But the early promise of such fisheries has not lasted, for example in the Sepik river, Papua New Guinea." According to Allen (1991), O. mossambicus, which was introduced to Papua New Guinea in 1954, is now abundant in Lower Ramu and Middle and Lower Sepik rivers. In Papua New Guinea, 329 fish species have been collected from freshwaters (Allen 1991). Of this total 13 species are introduced forms, and about 102 species are fishes that are believed to have a marine larval stage. The remaining species are purely freshwater indigenous fishes (Allen 1991). Although there have been detailed ichthyological surveys in Papua New Guinea (Roberts 1978; Glucksman et al. 1976; Allen 1991), no scientific evidence was found of any adverse impact of $O$. mossambicus on the indigenous fish fauna. The fact is that this introduced African tilapia, which occurs exclusively in the floodplains and oxbows of rivers (David Coates pers. comm. 2002), is now an important source of food for people along the Sepik and Ramu rivers and their major lowland tributaries (Allen 1991).

The strangest case involving policy regarding fish introductions is that reported by Maclean (1988). He as editor of the Journal NAGA was threatened with libel if he published any papers about fish introductions (Maclean 1988). Presumably, the person threatening the libel suit meant articles favourable to fish introductions. Sreenivasan \& Chandrasekaran (1989) have claimed that there is unimpeachable evidence that tilapias have affected Chanos chanos. Forsskil (milkfish) culture. However the evidence they provide is scanty and the negative effects of tilapias did not always occur. Milkfish collected from seashores are cultured especially in brackish waters in the Philippines and Indonesia. The case that the two authors make is based on a more tenuous culture in ponds, temple moats and similar situations. Milkfish culture pursued for 40 years in Sri Lanka (and perhaps India too) has been a failure by and large. To blame tilapias for this failure 
on anecdotal evidence is not logical. The same two authors quote a paper by Rosenthal (1976), "Tilapia is the worst pest in ponds in the Philippines causing injuries to milkfish. Even if the standing crop is very high, it will be largely trash fish". The tilapia production in the Philippines is now about 100,000 tons annually. The impact of tilapias on milkfish culture remains unanswered but the milkfish production is around 200,000 tons a year now (Guerrero pers. comm 2000). According to Guerrero (pers. comm. 2000), after introduction of $O$. niloticus into freshwaters in the Philippines, $O$. mossambicus has become restricted to brackishwater habitats to which $O$. niloticus does not enter. As $O$. niloticus does not enter brackish waters, it is unlikely that this species poses any threat to milkfish culture in brackish waters in the Philippines. On the other hand, as there is a high production $(200,000 \mathrm{t} / \mathrm{yr})$ from milkfish culture in brackishwaters in the Philippines where O. mossambicus also occurs, Rosenthal's (1976) argument quoted by Sreenivasan \& Chandrasekaran (1989) that tilapia is the worst pest in milkfish culture ponds, appears to be not based on scientific evidence. Incidentally Rosenthal (1979) suggested the introduction of the European fish Tinca tinca to Sri Lanka freshwaters. Here the point is that while condemning tilapias as trash fish (Rosenthal 1976), introduction of a European fish has been advocated. Tinca tinca has had minimal effects on fish yields in India and disappeared from cooler waters where it was introduced (Sreenivasan 1989), while tilapias have made a substantial though sometimes controversial contribution in reservoirs in India (Sreenivasan \& Chandrasekeran, 1989). Sarnita (1999) reported that Tinca tinca introduced from the Netherlands to Indonesia in 1927, is not appreciated as food fish by people. On the other hand, $O$. mossambicus and $O$. niloticus introduced to Indonesia in 1939 and 1969 respectively contribute significantly to inland fish production (Samita 1999). China produced $400,000 \mathrm{t}$, Philippines $100,000 \mathrm{t}$ and Taiwan another $60,000 \mathrm{t}$ of tilapia in the late nineteen nineties (Fernando \& Halwart 2000).

Fish introductions, or for that matter any introductions of exotic plants and animals, are sometimes considered to be an unmitigated hazard. It is very natural to consider that the spread of exotic species in the ecosystems is often a matter of great concern, because in many cases especially when past information is not available, the effect of the invaders on the native biota cannot be predicted. This attitude may even be considered politically correct as discussed by Dawson (1998). This view often seems to be stemming from a "Panglossian" view according to which what is present in a situation is the best and should not be disturbed and this includes the introduction of exotics. However, an eminent ecologist Charles Elton (1958) said, "Conservation is a protean word, for it can mean on the one hand protection of wild species against the advances of human exploitation, alternatively the methods for attaining the highest productivity from exploited lands. We must be clear as to what type of conservation is meant when it is talked about. If the lines of argument in this book [His book] are sound, I believe that conservation should mean the keeping or putting in the landscape of the greatest ecological variety in the world, in every continent or island and as far as possible in every district, and provided 
that the native species have their place. I see no reason why the reconstruction of communities to make them rich and interesting and stable should not include a careful selection of exotics especially as these are going to arrive in due course and occupy some niche." This is in fact a controversial quote, but in our opinion the introduction of African tilapias into countries like Sri Lanka has been beneficial socio-economically and there is no scientific evidence still to conform that it has caused significant damage to the environment. Referring specifically to freshwater fishes, Lévêque (1998) states that over the past twenty years, a growing awareness of biotas in East African ancient lakes has been perceived. The consequence is that any planned introduction is viewed as a potential catastrophe and both ecological and economic potential values are not objectively considered. What he says of East Africa applies to tropical Asia and America where ancient lakes do not exist. Leveque (2002) points out that tilapia introductions in the tropics have been of great benefit as an economic resource in Asia and South America.

\section{Conclusions}

It is a fact that global biodiversity is threatened due to various natural and anthropogenic activities which change and despoil ecosystems. Changes and despoiling of the global ecosystems have been occurring at an accelerated rate since the twentieth century due to human population growth and technological advancement (UNEP, 1995). Dudgeon (1992) has shown that the major threats to river ecosystems in Asia are the degradation of river basins (particularly through deforestation and overgrazing), environmental damage due to river regulation and pollution effects. Tilapias originally from Africa have also been spread widely throughout the tropics and subtropics in natural waters and even more widely in culture during the last century. They have made inland capture fisheries viable in many countries where there was no such fishery before. Their role in fish culture has been very significant and is growing. We have examined claims of damage done by tilapias or their lack of value in capture and culture fisheries and find these claims include rare cases compared to many cases world wide of positive impacts and cases where negative impacts have been reported on indigenous fishes are often based on inadequate data. Introductions of exotics do have impacts on indigenous organisms but one has to weigh the positive and negative aspects as seen over the past and compare them. It appears that the positive role of exotics in the world has been sometimes downplayed and the risks greatly exaggerated. In Asian countries such as Sri Lanka, Philippines, Indonesia and Thailand, introduction of tilapias to lacustrine waters has been greatly beneficial socio-economically. According to Guerrero (1999), the impact of introduced tilapia on endemic and indigenous fishes in the Philippine lakes and reservoirs has been positive in terms of contributing to fish production. He has also mentioned that there are no indications of any adverse effects of tilapias on the unique fish fauma of the Philippine lakes. Although there are some publications on negative impacts of tilapias on indigenous fish fauna 
(Sreenivasan 1989; Pethiyagoda 1994, 1999), more comprehensive analyses indicate that there are no significant negative impacts of introduced tilapias on indigenous fish fauna (Amarasinghe \& De Silva 1992; Fernando 1993; Baluyut 1999; Guerrero 1999; Sarnita 1999). Lastly but not least, tilapias have been in natural and artificial habitats throughout the tropies and the sub-tropics for over 50 years. No well-substantiated case of their damaging indigenous fish communities has so far been recorded though some cases have been cited of their negative impact. That some negative impacts have occurred in such a widely introduced species is to be expected but the benefits of introductions far outweigh these few isolated negative effects.

\section{Acknowledgements}

We are thankful to Dr. Rafael Guerrero III, the Executive Director of the Philippine Council for Aquatic and Marine Research and Development (PCAMRD) for his useful comments on the impact of tilapias on the indigenous fish fauna. Juraj Holcik, Bratislave, Slovakia kindly read and commented on the paper. David Coates, Vietnam, responded immediately to our query as to the actual location of tilapias introduced into the Sepik river system. Julian Hynes, Toronto and Ghana, read the paper with meticulously and eliminated some mistakes. Some of the data presented in this paper were collected during field studies carried out under the research grants awarded by National Science Foundation of Sri Lanka (Project Number. RG/MAB/98/03) to the University of Kelaniya (M.J.S.W.) and (Project Number: RG/95/B/8) to the University of Ruhuna (P.R.T.C), and Swedish Agency for Research and Economic Cooperation (SAREC) to the University of Ruhuna (P.R.T.C.).

\section{References}

Allen, K.R. 1971

The relationship between production and biomass. Journal of the Fisheries Resarch Board Canada, 28: 1573-1581.

Allen, G.R. 1991

Field Guide to the Freshwater Fishes of Papua New Guinea. - Publication No. 9, Christensen Research Institute, Madang, Papua New Guinea, 268 p. Amarasinghe, U.S. 1987.

Fish yields of some down-stream reservoirs of the Mahaweli basin, Sri Lanka. Paper presented at the Workshop on Limnology and Fishery of the Mahaweli basin: a modified ecosystem, November 1987, Institute of Fundamental Studies, Kandy, Sri Lanka.

Amarasinghe, U.S. \& S.S. De Silva 1992

Cichlidae verses Cyprinidae: Experience from the inland fishery of Sri Lanka. FAO Fisheries Report, 458 (Supplement): 218-237. 
Arthington, A.H. 1989

Annual Report, Centre for catchment and in-stream research, Griffiths University for 1987-88. Part 4. Supporting documents. $4 \mathrm{p}$.

Baluyut, E.A. 1999

Introduction and fish stocking in lakes and reservoirs in Southeast Asia: a review. In: Fish and Fisheries of Lakes and Reservoirs in Southeast Asia and Africa (W.L.T. van Densen \& M.J. Morris eds), pp. 117-141, Westbury Publishing, Otley.

Beveridge, M.C. M. \& B.J. McAndrew (ed) 2000.

Tilapias: biology and exploitation. Fish and Fisheries Series 25: Kluwer Academic Publishers, Dordrecht 505 pp.

Bludhorn, D. R. \& A.H. Arthington 1990

Somatic characteristics of the Australian population of Oreochromis mosssambicus (Pisces: Cichlidae). Environmental Biology of Fishes, 29: 277-291.

Chandrasoma, J. \& S.S. De Silva 1981

Reproductive biology of Puntius sarana, an indigenous species and Tilapia rendalli, an exotic, in an ancient man-made lake in Sri Lanka. Fisheries Management 12: 17-28.

Coates, D. 1992

Review of tilapia in Papua New Guinea. FAO Fisheries Report, 458 (Supplement): 192-196.

Coates, D. 2002

Pers. Comm.

Costa, H.H. \& M.J.S. Wijeyaratne 1989

Epidemiology of the epizootic ulcerative syndrome occurring for the first time among fish in Sri Lanka. Journal of Applied Iehthyology, 5(1): 48-52.

Dawson, T.J. 1998

The tension between scientific objectivity and political correctness. In: Ethics, money and politics (D. Lunney \& T.J. Dawson eds), pp. 1-4, Publications of Royal Society, NSW.

De Silva, S.S. \& U.S. Amarasinghe 1990

Stunting in Oreochromis mossambicus (Peters) (Pisces, Cichlidae): an evaluation of past and recent data from Sri Lankan reservoir populations.Journal of Applied Ichthyology 5: 203-210.

De Silva, S.S. \& C.H. Fernando 1980

Recent trends in the fishery of Parakrama Samudra, an ancient man-made lake in Sri Lanka. In: Tropical Ecology and Development (J.I. Furtado ed.), pp. 927-937. University of Malaya Press, Kuala Lumpur.

De Zylva, E.R.A. 1999

The introduction of exotic fish in Sri Lanka with special reference to tilapias. NAGA, The ICLARM Quarterly (Manila), 22(3): 4-8. 
Dudgeon, D. 1992

Endangered ecosystems: a review of the conservation status of tropical Asian rivers. Hydrobiologia, 248: 167-191.

Dudgeon, D. 2000.

The ecology of tropical Asian rivers and streams in relation to biodiversity conservation. Annual Review of Ecology and Systematics 31: 239-262.

Elton, C. 1958

The ecology of invasions by animals and plants. Methuen, London $181 \mathrm{p}$.

Fernando, C.H. 1993

Impact of Sri Lankan reservoirs, their fisheries, management and conservation. In: Ecology and Landscape management in Sri Lanka (W. Erdelen, C. Preu, N. Ishwaren \& C.M. Madduma Bandara eds), pp. 351374, Josef Margraf Verlag, Weikersheim.

Femando, C.H. 2000

A View of the inland fisheries of Sri Lanka: Past, present and future. Sri Lanka Journal of Aquatic Sciences, 5: 1-26.

Fernando, C.H. \& H. Halwart 2000a

Possibilities for the integration of fish farming into irrigation'systems. Fisheries Management and Ecology, 7: 45-54.

Fernando, C.H. \& H. Halwart 2000b

Fish farming in irrigation systems: Sri Lanka and global view. Sri Lanka Journal of Aquatic Sciences 6: 1-74.

Fernando, C.H. \& J. Holčik 1991

Fish in reservoirs. International Revue gesamtan Hydrobiologie, 76: 149167.

Fernando, C.H. \& H.H.A. Indrasena 1969

The freshwater fisheries of Ceylon. Bulletin of the Fisheries Research Station, Ceylon, 20: 101-134.

Fernando, C. H., J.J.S. Gurgel \& N.A.G. Moyo 1998

A global view of reservoir fisheries. International Review of Hydrobiology 83: $31-42$.

Fishelson L. \& Z. Yaron (eds) 1983

International Symposium on Tilapia in Aquaculture. Tel Aviv University, Tel Aviv, 624 p.

Fitzsimmons, K. (ed.) 1997

Tilapia aquaculture. Proceedings of the Fourth International Symposium on Tilapia in Aquaculture, Northwest Regional Agricultural Engineering Service (NRAES) Cooperative Extension, Volume 2, Ithaca, New York, $808 \mathrm{p}$.

Fitzsimmons, K. \& J.C. Filho (eds) 2000

Tilapia culture in the 21 st century. Froceedings from the Fifth International Symposium on Tilapia in Aquaculture. September 2000, Rio de Janeiro, $682 \mathrm{p}$. 
Tilapia and indigenous fish in Sri Lanka

Guerrero, R.D. III 1999

Impacts of tilapia introductions on the endemic fishes in some Philippine lakes and reservoirs. In: Fish and fisheries of lakes and reservoirs in Southeast Asia and Africa, (W.L.T. Van Densen \& M.J. Morris eds), pp. 151-157, Westbury Publishing, Otley.

Glucksman, J., G. West \& T.M. Berra 1976

The introduced fishes of Papua New Guinea with special reference to Tilapia mossambica. Biological Conservation 9: 37-44.

Goudswaard, P.C., F.Witte \& E.F.B. Katunzi 2002.

The Tilapiine fish stocks of Lake Victoria before and after the Nile perch upsurge. Journal of Fish Biology 60: 838-856.

Horn H.S. 1978

Optimal tactics of reproduction and life-history. In: Behavioural Ecology: An evolutionary approach (J.R. Krebs \& N.B. Davies eds), pp. 411-429, Blackwell Science Publishers, Oxford.

Jang,M.H., J.G. Kim, S.B. Park, K.S. Jeong, G.I. Cho \& G.J. Joo 2002.

The current status of the distribution of introduced fish in large river systems in South Korea. International Review of Hydrobiology 87: 319 328.

Kortmulder, K., E.J. Feldburgge \& S.S. De Silva 1978

A combined field study of Barbus (=Puntius) nigrofasciatus Gunther (Pisces, Cyprinidae) and water chemistry of its habitats in Sri Lanka. Netherlands Journal of Zoology 28: 111-131.

Lévêque, C. 1998

Biodiversity dynamics and conservation of the freshwater fish of tropical Africa. Cambridge University Press, Cambridge. 451 pp.

Leveque,C.2002.

Book critique: Out of Africa: the success story of tilapias. Environmental Biology of Fishes 64: 461-464.

Lowe-McConnell, R.H. 1975

Fish communities in tropical freshwaters. Longman, London, 337 p.

Lowe-McConnell, R. H. 1982

Tilapias in fish communities. In: The Biology and Culture of Tilapias, (R.S.V.Pullin \& R.H. Lowe-McConnell eds), pp. 83-113, ICLARM Conference Proceedings 7, ICLARM, Manila.

Lowe-McConnell, R. H. 1987

Ecological studies on tropical fish communities. Cambridge University Press, Cambridge. 387p.

Maclean, J.L. 1988

Fish introductions (Editorial). NAGA, The ICLARM Quarterly, Manila, 11(4): 2 . 
McAndrew B.J. 2000

Evolution, phylogenetic relationships and biogeography. In: Beveridge M.C.M. and McAndrew B.J. (eds) Tilapias: Biology and Exploitation. Kluwer Academic Publishers, Dordrechr. 1-32.

Myers, G.S.1955

Notes on the fish fauna of middle Central America with special reference to pond culture of tilapias. FAO Fisheries Technical Paper, 2: 5-8.

Pethiyagoda, R. 1991

Freshwater fishes of Sri Lanka. The Wildlife Heritage Trust of Sri Lanka, Colombo, $362 \mathrm{p}$.

Pethiyagoda, R. 1994

Threats to the indigenous freshwater fishes of Sri Lanka and remarks on their conservation. Hydrobiologia, 285: 189-201.

Pethiyagoda, R. 1999

Fishes in trouble: The decline and fall of Sri Lanka's freshwater fish fauna. Loris, Journal of Wildlife and Nature Protection Society of Sri Lanka, 22(2): 56-64.

Petr, T.(ed) 1988.

The use of cyprinids in the management of larger inland waters of the IndoPacific Region. FAO Conference Proceedings, Kathmandu, Nepal. FAO Fisheries Report FIRI/405 Supplement 179 pp.

Pianka, E.R. 1970

On the r- and K-selection. American Naturalist 104: 592-597.

Pullin R.S.V, T. Bhukaswan, M. Tonguthai \& J.L. Maclean (eds) 1986

The Second International Symposium on Tilapia in Aquaculture. ICLARM Conference Proceedings 15, ICLARM, Manila, 623 p.

Pullin R.S.V., J. Lazard, M. Legendre, J.B. Amon Kothias \& D. Pauly (eds) 1996

The Third International Symposium on Tilapia in Aquaculture. ICLARM Conference Proceedings, ICLARM, Manila, 575 p.

Pullin, R.S.V., M.L. Palomores, C.V. Casal, M.M. Dey, \& D. Pauly 1997

Environmental impact of tilapias. In: Tilapia aquaculture (K. Fritzsimmons ed.), pp. 554-570, Proceedings of the Fourth International Symposium on Tilapia in Aquaculture, Northwest Regional Agricultural Engineering Service (NRAES) Cooperative Extension, Volume 2, Ithaca, New York.

Reidel, D. 1979

Some remarks on the fecundity of tilapia (Tilapia mossambica Peters) and its introduction into Middle Central America (Nicaragua) together with the first contribution towards the limnology of Nicaragua. Hydrobiologia, 25: 357-388.

Roberts, T.R. 1978

An ichthyological survey of the Fly River in Papua New Guinea with description of new species. Smithsonian Contributions in Zoology, 281: 172. 
Tilapia and indigenous fish in Sri Lanka

Rosenthal, H. 1976

Quoted in Sreenivasan and Chandrasekeran 1989

Rosenthal, H 1979

Preliminary report and recommendations on reservoir and tank stocking activities in inland fisheries. 30 July 1979, Ministry of Fisheries, Galle Face, Colombo.

Sarnita, A.S. 1999

Introduction and stocking of freshwater fishes into inland waters of Indonesia. In: Fish and fisheries of lakes and reservoirs in Southeast Asia and Africa ( W.L.T Van Densen \& M.J. Morris eds), pp. 143-150, Westbury Publishing, Otley.

Smith, M. \& F. Jiffry 1986

The reproductive strategy of Labeo dussumieri and implications of hydroelectric and irrigation projects on the Mahaweli Ganga, Sri Lanka. In: The First Asian Fisheries Forum (J. Maclean, L.B. Dizon, \& L.V. Hosillos eds), pp. 693-696, Asian Fisheries Society, Manila.

Sreenivasan, A. 1989

Status of some exotic fish introductions in Tamil Nadu. In: Exotic Aquatic Species in India (M. Mohan Joseph ed.), pp. 59-62, Proceedings of the Workshop on Exotic Aquatic Species in India, Special Publication 1. Asian Fisheries Society Indian Branch, Mangalore.

Sreenivasan, A. \& F. Chandrasekaran 1989

Status of tilapia in Tamil Nadu. In: Exotic Aquatic Species in India (M. Mohan Joseph ed.), pp.67-74, Proceedings of the Workshop on Exotic Aquatic Species in India, Special Publication 1. Asian Fisheries Society Indian Branch, Mangalore.

Trewavas, E. 1986

Tilapiine fishes of the genera Sarotherodon, Oreochromis and Danakilia.

UNEP, 1995 British Museum (Natural History), 583 p.

Global Biodiversity Assessment. Published for United Nations Environment Programme, Cambridge University Press, Cambridge, 1140 p.

Vaas, K.F. \& M. Sachlan 1952

Notes on fisheries exploitation of the artificial lake Tjiburuj in West Java. Contribution of the Agricultural Research Station, Bogor, No. 132, 1-22.

Welcomme, R.L. 1988

International introductions of inland aquatic species. FAO Fisheries Technical Paper 294: 318p.

Welcomme, R.L. 1992

A history of international introductions of inland aquatic species. ICES Marine Science Symposium 194: 3-14. 
Welcomme, R.L. \& D.M. Bartley 1998

Current approaches to the enhancement of fisheries. Fisheries Management and Ecology 5: 351-382.

Wijeyaratne, M.J.S. 1993

Conservation of freshwater fish biodiversity in Sri Lanka. Conservation and Sustainable Development, School of Natural Resources and Environment, University of Michigan 1: 61-73.

Winkler, H. 1983

The ecology of cormorants (genus Phalacrocorax). In: Limnology of Parakrama Samudra-Sri Lanka: a case study of an ancient man-made lake in the tropies (F. Schiemer ed.), pp. 193-199. Dr. W. Junk Publishers, The Hague. 
